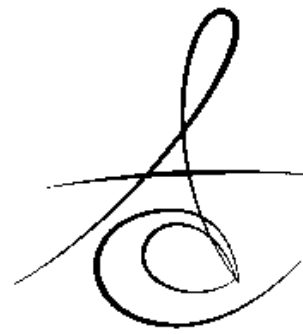

\title{
İMMEDİYAT İMPLANT YÜKLEME PROTOKOLÜ:GÜNCEL YAKLAŞIMLAR
}

IMMEDIYAT IMPLANT LOADING PROTOCOL: CURRENT APPROACHES

Dr. Gizem Nur BAĞRIVATAN*

Doc.Dr. Altuğ CílíngİR*

\author{
Dr. Melehat ÇELİK*
}

Prof. Dr. Gülșen BAYRAKTAR*

Makale Kodu/Article code: 1306

Makale Gönderilme tarihi: 1309.2013

Kabul Tarihi: 30.12.2013

\section{ÖZET}

İmplant üstü protezler; immediyat, erken, geleneksel, kademeli ve geç olmak üzere farkı zamanlarda yüklenebilirler. İmmediyat yükleme protokolü özellikle tek diş eksikliklerinde yumuşak doku şekillenmesi sağladığı için estetik sonuçlar alınmasını sağlar. Bu çalışmada tam dişsiz bireylerde immediyat implant yüklenmesi ile sabit protetik tedavilerin yapılmasını sağlayan ve son yıllarda güncel olarak uygulamaları sunulan All On Four sistemleri değerlendirilmektedir.

Anahtar Kelimeler: İmmediyat yükleme, dental implantlar, yükleme protokolleri.

\section{ABSTRACT}

Implant supported prostheses may be loaded at different time protocols as; immediate, early, conventional, progressive and delayed. Immediate loading helps maintaining esthetic results especially replacing anterior region teeth. The goal of this study to evaluate the recent immediate implant loading methods in edentulous patients which are treated with fixed prostheses (All On Four System).

Key words: Immediate load, dental implants, loading protocols.

\section{GİRİS}

İmmediyat yükleme; implantların yerleştirilmesinden 48 saat içerisinde yüklenmesidir. Erken yükleme; 48 saat ve ilk 3 aylık zaman süreci arasında implantların yüklenmesidir. Bunların yanı sıra kademeli yükleme protokolü de literatürde mevcuttur. Kademeli yükleme denilince implantların fonksiyona yavaş yavaş getirildiği anlaşılır. Konvansiyonel yüklemede implantlar cerrahiden 3 ay sonra yüklenirler. Geç yükleme denildiğinde ise 3 ve 6 aylık süre zarfında yapılan yüklemeler anlaşılmaktadır ${ }^{1,2}$.

İmplantoloji ilk uygulamalarından günümüze kadar hızlı bir değişim ve gelişim süreci geçirmiştir. 1960-70'li yıllar implantolojide gelişim periyodudur. Bu süreçte osseointegrasyon ve primer stabilite konuları üzerinde durulmuş, implantların üst yapıları için belirli sürelerin beklenmesi tedavinin kaçınılmaz bir gereği olarak kabul edilmiştir. İkinci periyot olan 1980-90 yılları keşif periyodu olarak kabul edilmekle beraber, bu yıllarda cerrahi yöntemler geliştirilmiş ve implantların yüzey özelliklerinin geliştirilmesi suretiyle osseointegrasyonun arttırılması amaçlanmıştır. 2000'li yıllardan günümüze kadar olan çalışmalarda ise; implantların osseointegrasyon sürelerinin kısaltılması ve/ veya immediyat yüklenmesi, protetik tedavilerde implantların kademeli yüklenmesi ve yumuşak doku şekillendirmeleri gündemde olmuştur. Bu dönem de ilerleme periyodu olarak tanımlanmaktadır ${ }^{1}$.

İmplantlar protetik tedavilerinin zamanlama farkılığı ile değişik protokolollerde yüklenebilirler. İmmediyat yükleme; planlanan restorasyonun implant uygulamasından sonraki ilk 48 saat içinde yerleştirilmesi ve restorasyonun oklüzyonda karşıt çenedeki dişlerle temasta bırakılmasıdır ${ }^{2}$. İmmediyat yükleme, ilk olarak 1979 yılında Ladermann tarafından uygulanmıştır. Ladermann, interforaminal bölgeye 4 implant

* İstanbul Üniversitesi, Diş Hekimliği Fakültesi, ProtetikDiş Tedavisi Anabilim Dalı 
yerleştirip aynı gün bar üzeri overdenture protezi uygulamış ve restorasyonda oklüzal ilişki oluşturmuştur. $^{3-6}$

\author{
İmmediyat Yükleme Protoklolünün \\ Endikasyonunda Etkili Faktörler \\ - İmplantın bulunduğu bölgedeki kemik tipi \\ - Çekim soketine yerleşim zamanı (Hemen \\ çekim sonrası veya iyileşmeden sonra) \\ - İmplant tipi ve yüzey özellikleri \\ - İmplant uzunluğu \\ - Primer stabilite \\ - Protetik restorasyon seçimi $7,8$.
}

İmmediyat Yükleme Protokolünün
Kontrendikasyonunda Etkili Faktörler
- $\quad$ Primer stabilite sağlanamaması
- Kötü ağız hijyeni
- İnce diş eti biyotipi
- Çekim soketinde enfeksiyon varlığı
- Bruksizm
- Agresif periodontitis
- Sigara içilmesi olarak belirtilmektedir?.

Tek Diş Eksikliğinde İmmediyat Yükleme

Hartog ve ark. $^{4}$; tek diş eksikliği olgularında, immediyat ve erken yükleme protokollerini konvansiyonel yöntemle karşılaştırarark yayınladıkları derlemelerinde, yayınlanmış 19 adet çalışmanın sonuçlarını değerlendirmişlerdir. Bu çalışmalardan $5^{\prime} \mathrm{i}$ randomize klinik tedavi, 2'si klinik çalışmanın ve 12 'si olgu serisidir. Yazarlar bir yıl takipli çalışma sonuçlarına göre immediyat, erken ve konvansiyonel yükleme yöntemleri arasında anlamlı bir farklılık oluşmadığını belirlemişler ve immediyat yüklemenin konvansiyonel yükleme protokolüne bir alternatif olabileceğini bildirmişlerdir.

Tek diş eksikliklerinde immediyat yüklemenin en büyük avantajı yumuşak doku şekillenmesinin sağlanabilmesidir. İmmediyat yüklenmiş ön bölge implantlarında uygulanan geçici akrilik kuronların, diş etinin estetik açıdan tatmin edici boyutlarda iyileşmesini sağlayabildiği bildirilmektedir. Bununla birlikte immediyat yüklenmiş ön bölge implantlarında uygulanan geçici akrilik kuronların diş etine fazla baskı yapması sonucunda dişetinde çekilmelerin olabileceği ve geçici kuronların lateral ve protrusiv hareketlerdeki erken temaslardan korunması gerektiği bildirilmektedir ${ }^{7}$.

\section{TAM DİŞSİZLİKTE İMMEDİYAT YÜKLEME Nobel Biocare-All On Four Sistemi}

1998 yilında Portekizli bir diş hekimi olan Paulo Malo tarafindan ilk kez uygulanan bu sistemde amaç; tam dişsiz maksilla ve mandibulada 4 adet implant üzerine sabit restorasyon yapabilmektedir. All-on four sistem 'cornerstone' yani köşetaşı taşı olarak adlandırılan alt çenede mental foraminalar arasına üst çenede maksiller sinüs duvarına paralel yerleştirilmiş, ikisi aksiyal diğer ikisi de $30^{\circ}-45^{\circ}$ açılara sahip açılı implantlar üzerine immediyat yükleme ile sabit protetik restorasyon yapılmasıdır ${ }^{9}$.

\section{All On Four ve benzer sistemler ile;Kemik} ogmentasyonu

- Sinir repozisyonu, sinir hasarı

- Sinüs lifting

- Greft alınan bölge nekrozu

- Sinüzit

- Fistül

- Greft kaybı

- İmplant kaybı

- Osteomiyelit

- Cerrahi komplikasyonlar

gibi durumlardan kaçınılması ve aynı zamanda implant sayısı da azalacağı için maliyetin düşürülmesi amaçlanmaktadır.

Malo ve ark. ${ }^{10} 2011$ ylında yayınladıkları çalışmalarında; 245 hastada mandibulada All on four sistemi ile yüklenmiş 980 implantın 10 yllık klinik takibini gerçekleştirmişlerdir. Çalışma sonuçlarında, 13 hastada 21 implant kaybı olduğunu, implantların 5 yıllık başarılarının \% 98. 1, 10 yıllık başarı oranının \% 94. 8, 10 yıl sonunda protetik başarı oranının \% 99. 2 olduğunu bildirmişlerdir.

Babbush ve ark. ${ }^{11} 2011$ yılında yayınladıkları çalışmalarında; 165 hastada 708 Nobel Active implantları All on four sistemi ile immediyat olarak yüklemişler ve 29 aylık takip sonuçlarını değerlendirmişerdir. Bu çalışmada 436 implant maksillaya, 272 implant mandibulaya yerleştirilmiş olup, 12 hastada protetik tedaviler hem maksilla hem de mandibulada birlikte gerçekleştirilmiştir. Çalışmada klinik değerlendirmeler 3, 6, 12, 18, 24. ve 29. aylarda yapılmışır. Toplamda 3 adet implant ilk 12 ay içerisinde kaybedilmiş, implantların 29 ay sonundaki başarıoranı $\% 99.2$ olarak bildirilmiştir.

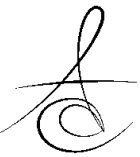


Malo ve ark. ${ }^{12}$, 2012 yılında yayınladıkları çalışmalarında tam dişsiz maksillada All on four sistemi ile immediyat yükleme protokolünü uyguladıkları hastaların 3 ve 5 yıllık klinik takip sonuçlarını bildirmişlerdir. Bu çalışmada 242 hastaya 968 implant yerleştirilmiş ve 18 hasta vefat ettiğinden 72 implant çalışma dışı kalmıştır. Çalışmanın birinci yıl takip sonuçlarında; 12 tanesi açılı, 7 tanesi ise düz olmak üzere toplam 19 implantın kaybedildiği, implant kaybı olan hastaların büyük çoğunluğunda diabet, tansiyon, sigara kullanımı, HIV, hepatit C, bisfosfanat kullanımı gibi problemlerin olduğu saptanmıştır. 3 yıl sonundaki değerlendirmelerde 621 implantta ortalama $1.52 \mathrm{~mm}$, 40 implantta ise $3 \mathrm{~mm}$ den fazla kemik kaybı olduğu saptanmıştır. Araştırmanın beşinci yıl takip sonuçlarında ise; 33 implantta ortalama $1.95 \mathrm{~mm}, 14$ implantta ise $3 \mathrm{~mm}$ den fazla kemik kaybı olduğu belirlenmiştir. 5 hastada geçici protezlerde kırık, 1 hastada abutment vidasında, 1 hastada protez vidasında gevşeme, 1 hastada hem abutment hem de protez vidasında aşınma tespit edilmiş olup, 5 yıl sonunda implant başarı oranı \%98 ve protez başarı oranı ise $\% 100$ olarak saptanmıştır.

Galindo ve ark. ${ }^{13} 2012$ yılında yayınladıkları çalışmalarında, mandibulada All on four sistemi ile tedavi ettikleri 183 hastada 732 implant uygulanmış ve 1 yıllık takipleri yapılmıştır. Bir yıl sonunda hiçbir implantın çevresindeki marjinal kemik kaybının $1 \mathrm{~mm}$ den fazla olmadığı saptanmıştır. Bir yıl sonunda 1 implant kaybı görülmüş ve ortalama implant başarı oranı \% 99.86 olarak bildirilmiştir. 3 hastada immediyat protezde diş kırı̆ı̆, 1 hastada titanyum iskelet kırığı meydana gelmiştir. Protetik başarı oranı \% 98.9 olarak bildirilmiştir.

\section{Oluşabilecek Protetik Komplikasyonlar}

- Kısaltılmış diş arkından kaynaklanan yetersiz fonksiyon

- Geçici protezlerde kırık

- Estetik problemler

- Ağız hijyenin sürdürülememesi

- İmplant-protez kaybı olarak bildirilmektedir ${ }^{14}$. Agliardi ve ark. ${ }^{15} 2010$ yıllında yayınladıkları çalışmalarında, tam dişsiz hastalarda All on four sistemi ile immediyat yükleme protokollerinde yerleştirilen aksiyal ve açılı implantlar arasında marjinal kemik kaybı farklarını araştırmışlardır. Çalışmada 80'i erkek, 93'ü kadın toplam 173 tam dişsiz hasta geçici fonksiyonel akrilik protez ile immediyat yükleme yapılarak tedavi edilmiş olup, 6-12 ay fonksiyon sonrası takipleri 5 yıla kadar sürdürülmüştür. İlk 6 ayda maksillada 4'ü aksiyel, mandibulada 1'i açılı yerleştirilmiş implantlarda kayıp belirlenmiş ve 1 yıllık ortalama marjinal kemik kaybı miktarı maksillada (204 implant) $0.9+/-0.7 \mathrm{~mm}$; mandibulada (292 implant) 1.2+/-0.9 mm olarak ölçülmüş; ancak, aksiyel ve açılı implantların marjinal kemik kayıpları arasında istatiksel olarak anlamlı farklılık belirlenmemiştir. Parel ve ark. $^{16} 2011$ yılında yayınladıkları çalışmalarında; maksillada 4 implant ile immediyat yükleme uygulamalarındaki risk faktörlerini değerlendirmişlerdir. Çalışmada; sigara kullanımı, cinsiyet, karşıt diş arkı, kemik yoğunluğu ve hacmi, yerleştirme torkları ve sistemik faktörler incelenmiştir. Bu çalışma sonucunda; erkek hastaların, kemik yoğunluğunun az olmasının, karşıt arkta doğal diş bulunmasının, distal implantın bulunduğu bölge ve parafonksiyonların birincil derecede risk faktörü oluşturduğu saptanmış ve araştırmacılar immediyat yükleme yerine konvansiyonel yükleme protokolünün uygulanmasını önermişlerdir. Kemik hacminin azlığı ve sigara kullanımı ise sekonder risk faktörü olarak saptanmıştır. Yapılan bu çalışmanın sonucunda cerrahi öncesinde risk faktörlerinin değerlendirilmesinin ve belirlenmesinin gerektiği vurgulanmıştır. Bu çalışmada ayrıca; kemik kalitesi düşük ve karşıt arkta doğal dişler mevcut ise implant kayıplarının artığı da saptanmıştır. Araştırmacılar bu nedenle bruksizm olgularında implant sayısının arttırımasını, şüpheli durumlarda implantların veya zygoma implantlarının kullanılmasını önermektedirler.

Esposito ve ark. ${ }^{17}$, 2013 yılında yayınladıkları derlemede 22 çalışma ve 1024 hasta üzerinde immediyat, erken ve konvansiyonel yükleme protokollerini karşılaştırmışlardır. Çalışmanın sonucunda; immediyat yükleme protokolünün erken yüklemeden daha iyi, fakat immediyat yüklemedeki kayıp oranının konvansiyonelden daha fazla, oklüzal temas etkisinin ise belirsiz olduğu bildirilmiştir.

Degidi ve ark.'nın ${ }^{18}$ çalışmalarında; 253 total ve parsiyel dişsiz hastada (yaş aralığı 20-78, 147'si bayan ve 106'sı erkek); 702 Dentsply implantları, immediyat fonksiyonel, immediyat non fonksiyonel ve konvansiyonel yükleme yaparak karşılaştırmış ve değerlendirmişlerdir. 34 hastada 253 implant immediyat fonksiyonel, 63 hastada 135 implant non fonksiyonel ve 156 hastada 314 implant konvansiyonel protokol ile yüklenmiştir. Çalışma sonucunda;

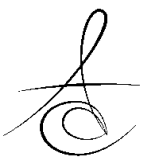


Atatürk Üniv. Diş Hek. Fak. Derg.

J Dent Fac Atatürk Uni

Supplement: 9, YIl: 2014, Sayfa : 169-174

yüklemeden 1 yıl sonra 1,5 mm.'den az marjinal kemik kaybı oluştuğu saptanmıştır. Başarı oranları; immediyat fonksiyonel yüklemede \% 99.2 (2/253 implant), immediyat non fonksiyonel yüklemede \% 99.2 (1/135 implant), konvansiyonel yüklemede ise \%99.4 (2/314 implant) olarak saptanmış olup gruplar arasında istatiksel olarak anlamlı farklılık belirlenmemiştir.

\section{İmmediyat Yüklemenin Avantajları:}

- Cerrahi müdahale sayısında azalma

- Tedavi süresinde kısalma

- Hastaların estetik ve fonksiyonel sıkıntılarında azalma

- Yumuşak doku estetiğinin sağlanabilmesi

- Marjinal kemik kaybında azalma olarak bildirilmektedir ${ }^{7}$.

Literatürde immediyat yüklenen implantlarda görülen kaybın geleneksel yüklenenlerden fazla, erken yüklenenlerden ise daha az olduğunu bildiren çalışmalar da mevcuttur ${ }^{4,17}$. Bunun yanı sıra bazı çalışmalarda ise; farklı zamanlarda yüklenmiş implantlarda histolojik, klinik ve radyografik açıdan farklılık bulunmadığı bildirilmektedir ${ }^{1}$. Bu konuda günümüzde kesin bir görüş birliği belirtilememektedir. Tüm yayınlar esas olarak klinik çalışmalarla desteklenmektedir. 2010 yılında yayınlanmış konsensus raporunda; maksillada hareketli protezlerle immediyat yüklemenin klinik olarak yeterince desteklenemediği ancak mandibulada hareketli protez ile implantüstü immediyat yüklemelerin klinik olarak başarılı olduğu bildirilmiştir. Sabit protezler ile immediyat yükleme ise hem maksilla hem de mandibulada klinik olarak başarılı olarak kabul edilmektedir. Her ne kadar klinik çalışmalar bu bulguları desteklemiş olsa da, bu sonuçlar henüz kesin olarak hem bilimsel ve hem de klinik onaya birlikte sahip değildirler. ${ }^{19}$

Çalışmalar immediyat yüklenen implantların fonksiyonda bırakılmalarından 3 yıl sonra başarı oranlarının hayli yüksek olduğunu saptamıştır (\%98$100)^{20,21,22,23,24,25}$. Ayrıca bazı çalışmalar çekim soketine yerleştirilmiş ve yüklenmiş tek implantlarda benzer oranda başarı sağlandığı bildirilmiştir. 20,21,23,26-30

İmmediyat yüklenen implantlar hastaların yaşam kalitesi üzerine olumlu etki yapabilir, çalışmalarda immediyat yükleme protokolünün hastaların yaşam kalitesini artırdığı rapor edilmiştir. 7,23,31-40
BAĞRIVATAN, ÇELİK,

ÇİLINGİR, BAYRAKTAR

\section{SONUÇLAR}

Günümüzde yükleme protokolleriyle ilgili olarak verilerin değerlendirmesi sonucunda; konvansiyonel yüklemeye göre immediyat ve erken yükleme ile daha iyi estetik sonuçlar alınmakta ve hasta memnuniyeti de daha fazla olmaktadır. Ancak; her vaka için ayrı bilimsel ve klinik risk değerlendirmesi yapılmalı ve immediyat yüklemenin riskli olacağı hastalarda konvansiyonel yöntemlere başvurulmalıdır. Ayrıca yükleme protokollerinin uzun dönem sonuçlarının karşılaştırılabilmesi için bilimsel verilerle desteklenmiş randomize klinik çalışma sayısı arttırılmalıdır.

\section{KAYNAKLAR}

1. Cochran D., The evidence for immediate loading of implants, J Evid Base Dent Pract 2006; 6:15563.

2. Grütter L. Belser C. Implant Loading Protocols For The Partially Edentulous Esthetic Zone-Int J Oral Maxillofac Implants 2009:24:169-79.

3. Askary A.E.S. Fundamentals of Esthetic Implant Dentistry Blackwell Munksgaard 2007; 201-7.

4. Hartog L, Slater JJ, Vissink A, Meijer HJ, Raghoebar GM. Treatment outcome of immediate, early and conventional single-tooth implants in the aesthetic zone: a systematic review of survival, bone level, soft-tissue, aesthetics and patient satisfaction. J Clin Periodontol 2008; 35: 1073-86.

5. Ledermann P., Bar-prosthetic management of the edentulous mandible by means of plasma-coated implantation with titanium screws 1979; 34: 90711.

6. Uribe R.,Penarrocha M., Balaguer J., Fulgueiras N., Immediate loading in oral implant, present situation, Med Oral Patol Oral Cir Bucal 2005; 10, 143-53.

7. Bilhan $E$, Sönmez $E$, Mumcu E, Bilgin T. Immediate loading: three cases with up to 38 months of clinical follow-up. Journal of Oral Implantology, 2009; 35, 2: 75-81.

8. Aydın C., Yılmaz H., Dental implantların immediyat yüklenmesi, Atatürk Üniv Diş Hek Fak Derg 2002; 12: $60-4$ 
9. Maló P., Rangert B., Nobre M., All-on-Four Immediate-Function Concept with Brånemark System Implants for Completely Edentulous Mandibles: A Retrospective Clinical Study, Clin Implant Dent R 2003; 5:2-9.

10. Malo $P$, de Araújo Nobre M, Lopes A, Moss SM, Molina GJ ,A longitudinal study of the survival of All-on-4 implants in the mandible with up to 10 years of follow-up. J Am Dent Assoc 2011; 142:310-20.

11. Babbush CA, Kutsko GT, Brokloff J., The all-onfour immediate function treatment concept with NobelActive implants: a retrospective study, Journal of Oral Implantology, 2011; 37, 4 :431-45

12. Malo P., Nobre M., Lopes A., All on-4 ImmediateFunction Concept for Completely Edentulous Maxillae: A clinical report on the medium (3 years) and long term (5 years) outcomes, Clin Implant Dent Relat Res 2012; 14 : 139-50.

13. Galindo DF, Butura CC. Immediately loaded mandibular fixed implant prostheses using the allon-four protocol: a report of 183 consecutively treated patients with 1 year of function in definitive prostheses. Int J Oral Maxillofac Implants 2012 7:628-33.

14. Patzelt SB, Bahat O, Reynolds MA, Strub JR., The All-on-Four Treatment Concept: A Systematic Review. Clin Implant Dent Relat Res 2013; 5. doi: 10.1111/cid.12068.

15. Agliardi E., Panigatti S.,Clerico M.,Villa C., Malo P., Immediate rehabilitation of the edentulous jaws with full fixed prostheses supported by four implants: interim results of a single cohort prospective study, Clin Oral Implants Res, 2010; 21:459-65.

16. Parel S.,Phillips W., A risk assessment treatment planning protocol for the four implant immediately loaded maxilla, J Prosthet Dent 2011; 106:359-66.

17. Esposito $M$, Grusovin MG, Maghaireh $H$, Worthington $\mathrm{HV}$, Interventions for replacing missing teeth: different times for loading dental implants, Cochrane Database of Syst Rev. 2013, 3. CD003878.

doi: 10.1002/14651858.CD003878.pub5.

18. Degidi M, Piattelli A. Comparative analysis study of 702 dental implants subjected to immediate functional loading and immediate nonfunctional loading to traditional healing periods with a follow- up of up to 24 months. Int J Oral Maxillofac Implants 2005; 20:99-107.

19. Wismejer D.,Casentini P., Gallucci G., Chiapasco M., ITI Treatment Guide, Loading protocols in implant dentistry edentulous patients, Quintessence Publishing 2010; 125-87.

20. Cooper LF, Raes F, Reside G], et al. Comparison of radiographic and clinical outcomes following immediate provisionalization of single-tooth dental implants placed in healed alveolar ridges and extraction sockets. Int J Oral Maxillofac Implants 2010;25:1222-32.

21. De Bruyn H, Raes F, Cooper LF, et al. Three-years clinical outcome of immediate provisionalization of single Osseospeed() implants in extraction sockets and healed ridges. Clin Oral Implants Res 2013;24:217-23.

22. Donati $M$, La Scala V, Billi $M$, et al. Immediate functional loading of implants in single tooth replacement: a prospective clinical multicenter study. Clin Oral Implants Res 2008;19:740-8.

23. Raes F, Cooper LF, Tarrida LG, Vandromme H, De Bruyn H. A case-control study assessing oralhealth-related quality of life after immediately loaded single implants in healed alveolar ridges or extraction sockets. Clin Oral Implants Res 2012;23:602-8.

24. Vervaeke S, Collaert B, De Bruyn H. Immediate loading of implants in the maxilla: survival and bone loss after at least 2 years in function. Int J Oral Maxillofac Implants 2013;28:216-21.

25. Oyama K, Kan JY, Rungcharassaeng K, Lozada J. Immediate provisionalization of 3.0-mm-diameter implants replacing single missing maxillary and mandibular incisors: 1-year prospective study. Int J Oral Maxillofac Implants 2012;27:173-80.

26. Crespi R, Cappare P, Gherlone E. Radiographic evaluation of marginal bone levels around platform-switched and non-platform-switched implants used in an immediate loading protocol. Int J Oral Maxillofac Implants 2009;24:920-6.

27. Norton MR. The influence of insertion torque on the survival of immediately placed and restored single-tooth implants. Int J Oral Maxillofac Implants 2011;26:1333-43.

28. Tsuda H, Rungcharassaeng $K$, Kan JY, et al. Periimplant tissue response following connective tissue and bone grafting in conjunction with immediate 
single-tooth replacement in the esthetic zone: A case series. Int J Oral Maxillofac Implants 2011;26:427-36.

29. Noelken R, Neffe BA, Kunkel M, Wagner W. Maintenance of marginal bone support and soft tissue esthetics at immediately provisionalized OsseoSpeed implants placed into extraction sites: 2-year results. Clin Oral Implants Res 2014;25:214-20.

30. Redemagni M, Cremonesi S, Garlini G, Maiorana C. Soft tissue stability with immediate implants and concave abutments. Eur J Esthet Dent 2009;4:32837.

31. Bressan E, Lops D. Conometric retention for complete fixed prosthesis supported by four implants: 2-years prospective study. Clin Oral Implants Res 2014;25:546-52.

32. Cooper LF, Moriarty JD, Guckes AD, et al. Five-year prospective evaluation of mandibular overdentures retained by two microthreaded, TiOblast nonsplinted implants and retentive ball anchors. Int J Oral Maxillofac Implants 2008;23:696-704.

33. De Bruyn H, Besseler J, Raes F, Vaneker M. Clinical outcome of overdenture treatment on two nonsubmerged and nonsplinted Astra Tech Microthread implants. Clin Impl Dent Rel Res 2009;11:81-9.

34. De Kok I, Chang K-H, Li T-S, Cooper LF. Comparison of threeimplant- supported fixed dentures and two-implant-retained overdentures in the edentulous mandible: A pilot study of treatment efficacy and patient satisfaction. Int J Oral Maxillofac Implants 2011;26:415-26.

35. Dierens M, Collaert B, Deschepper E, et al. Patientcentered outcome of immediately loaded implants in the rehabilitation of fully edentulous jaws. Clin Oral Implants Res 2009;20:1070-7.

36. Erkapers M, Ekstrand K, Baer RA, Toljanic JA, Thor A. Patient satisfaction following dental implant treatment with immediate loading in the edentulous atrophic maxilla. Int J Oral Maxillofac Implants 2011;26:356-64.

37. Mertens C, Steveling HG. Early and immediate loading of titanium implants with fluoride-modified surfaces: results of 5-year prospective study. Clin Oral Implants Res 2011;22:1354-60.

38. Raes F, Cosyn J, De Bruyn H. Clinical, aesthetic, and patient-related outcome of immediately loaded single implants in the anterior maxilla: A prospective study in extraction sockets, healed ridges, and grafted sites. Clin Impl Dent Rel Res 2013;15:819-35

39. Van Lierde $K$, Browaeys $H$, Corthals $P$, et al. Comparison of speech intelligibility, articulation and oromyofunctional behaviour in subjects with single-tooth implants, fixed implant prosthetics or conventional removable prostheses. J Oral Rehabil 2012;39:285-93.

40. Van Lierde KM, Corthals $\mathrm{P}$, Browaeys $\mathrm{H}$, et al. Impact of anterior single-tooth implants on quality of life, articulation and oromyofunctional behaviour: a pilot study. J Oral Rehabil 2011;38:170-5.

\author{
Yazışma Adresi: \\ Dr. Melahat ÇELİK \\ İstanbul Üniversitesi, \\ Diş Hekimliği Fakültesi, \\ Protetik Diş Tedavisi Anabilim Dalı \\ e-mail: melahatcelik_@hotmail.com
}

